\title{
Sexual assault and posttraumatic stress disorder: A review of the biological, psychological and sociological factors and treatments
}

\author{
Kaitlin A. Chivers-Wilson*
}

\begin{abstract}
Sexual assault occurs with alarming frequency in Canada. The prevalence of Posttraumatic Stress Disorder (PTSD) in assault survivors is drastically higher than the national prevalence of the disorder, which is a strong indication that the current therapies for sexualassault-related PTSD are in need of improvement. Increasing knowledge and understanding of the pathologies associated with rape trauma in biological, psychological and sociological domains will help to develop more effective treatments for survivors. A dysregulation of the HypothalamicPituitary-Adrenal (HPA) axis is observed in survivors of sexual assault and this may be a fundamental cause of the structural and functional abnormalities contributing to PTSD symptoms. Pharmacotherapies are available to treat PTSD; however, they are often inadequate or unwanted by the survivor. Psychological health is compromised following interpersonal trauma and many psychological therapies are available, but with varying efficacy. A person's cognitions have a dramatic effect on the onset, severity, and progress of PTSD following sexual assault. Sociological impacts of assault influence the development of PTSD through victim-blaming attitudes and the perpetuation of rape myths. Perceived positive regard and early social support is shown to be important to successful recovery. Education is vital in rape prevention and to foster a supportive environment for survivors. The biological, psychological and sociological impacts and treatments should not remain mutually exclusive. A better appreciation of the biopsychosocial repercussions of sexual assault will aid in developing a more holistic and individualized therapy to help alleviate the physical and emotional pain following the trauma of rape.
\end{abstract}

KEYWORDS: posttraumatic stress disorder, trauma, sexual assault, rape, pharmacotherapy.

\section{INTRODUCTION}

One woman is sexually assaulted in Canada every minute (1). Sexual assault is any form of sexual contact without voluntary consent andthat violates a person's sense of autonomy, control and mastery over their body

\footnotetext{
* To whom correspondence should be addressed: Kaitlin A. ChiversWilson, University of Alberta Sexual Assault Centre, 2-705 Students' Union Building, Edmonton, Alberta, Canada, T6G 2J7. Phone: 780-604-9697

Email:kaitlin@ualberta.ca
}

(2). At the University of Alberta, 21\% of students have reported at least one unwanted sexual experience (3). Sexual assault is widespread and occurs with alarming frequency.

Recovery from sexual- assault- related Posttraumatic Stress Disorder (PTSD) is not solely measured by eliminating symptoms or achieving specific outcomes. Healing from this trauma does not mean that the survivor will forget the experience or never again experience any symptoms. Rather, successful recovery is subjective and measured by whether the survivor 
increases his or her involvement in the present, acquires skills and attitudes to regain control of his of her life, forgive him or herself for guilt, shame and other negative cognitions, and gain stress reduction skills for overall better functioning (4). There are many factors involved in successful recovery, including the degree of support received, previous self-concept, personal strength, and professional treatment provided by the medical and justice systems (5). PTSD is one of the problems that may result from failure of the recovery process.

PTSD is caused by exposure to a traumatic event and intense psychological distress occurs as a result of reexperiencing the event (6). PTSD is diagnosed when symptoms last longer than one month (7). To prevent the distressing reactions, survivors will avoid stimuli that provoke these feelings and this avoidance behaviour can be severe enough to significantly impair daily life (8).

The consequences of a sexual assault may be manifested biologically, psychologically, and sociologically. By gaining a better appreciation of the repercussions of sexual assault, a holistic and individualized therapy can be developed to ameliorate the physical and emotional pain following the trauma. The issues facing individuals who have experienced sexual assault will be discussed and improvements in current treatments will be suggested, with hopes to develop more effective and holistic therapies in the future.

\section{POSTTRAUMATIC STRESS DISORDER}

The US National Comorbidity Survey Report estimates the lifetime prevalence of PTSD among North Americans to be $7.8 \%$ (9). The lifetime prevalence of PTSD for women who have been sexually assaulted is $50 \%$ (10). Moreover, sexual assault is the most frequent cause of PTSD in women, with one study reporting that 94\% of women experienced PTSD symptoms during the first two weeks after an assault (9).

The alarmingly high rate of PTSD in survivors of sexual assault is a strong indication that the current therapies for rape victims are inadequate and in need of improvement. There is no 'cookie cutter' treatment for every victim suffering with PTSD, as the disorder can manifest itself in many ways (8). It is important to consider the biological, psychological, and sociological impacts when developing effective treatment and intervention methods for sexual-assault-related PTSD.

\section{PTSD PATHOPHYSIOLOGY}

Before treatment for sexual-assault-related PTSD can be developed, an understanding of the pathophysiology of PTSD is critical. The dysregulation seen in individuals with PTSD can be observed and measured on all major systems of the body including the neural, endocrine and immune systems (6). The HypothalamicPituitary-Adrenal (HPA) axis plays a key regulatory function in the body, controlling all three systems through negative feedback inhibition. Cortisol is a major hormone of the HPA axis and is the primary stress hormone in the body. It is released when stimulated by Corticotropin Releasing Hormone (CRH) and inhibited via negative feedback acting at the hypothalamic and pituitary levels. Intense psychological trauma such as sexual abuse can cause changes in the body's response to stress by increasing levels of CRH and dysregulating the HPA axis $(11,12)$. This results in a decreased number of CRH receptors in the anterior pituitary, decreased pituitary responsiveness to $\mathrm{CRH}$, and disturbed negative feedback inhibition (13). Reduced responsiveness to $\mathrm{CRH}$ causes overactivation of the HPA axis and can disturb negative feedback by cortisol (Figure 1). Cortisol has widespread action and its dysregulation affects other neural systems including the mesocorticolimbic dopaminergic system, leading to inappropriate fear reactions and persistent mild depression (14).

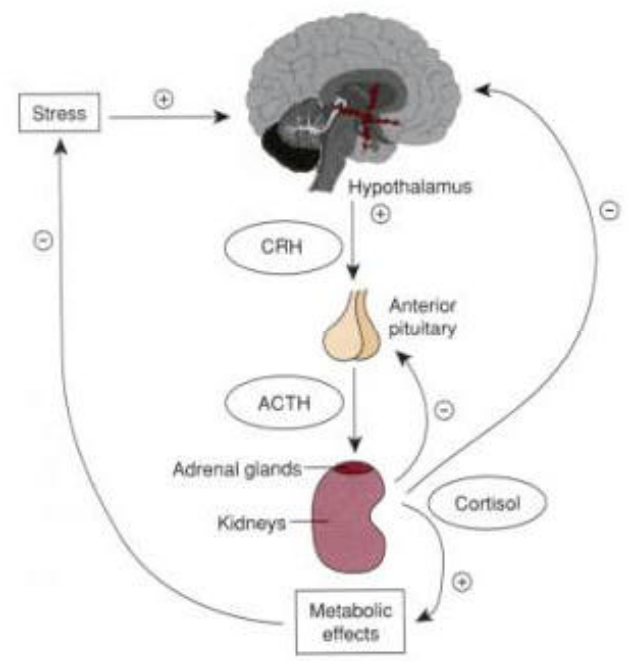

Figure 1. The hypothalamic-pituitary-adrenal axis

The HPA axis is dysregulated in survivors of sexual assault. A reduced responsiveness to $\mathrm{CRH}$ is observed and the negative feedback by cortisol on the hypothalamus and pituitary is disturbed.

[Retrieved April 9th, 2006 from

http://www.montana.edu/wwwai/imsd/alcohol/Vanessa/vwhpa_files/i mage003.jpg]

\section{PHARMACOTHERAPY TREATMENT OPTIONS FOR PTSD}

Knowledge of the biological changes with PTSD has led to the development of new treatments that offer more comprehensive management of PTSD and enable patients to enjoy an improved quality of life (11). For 
example, various drug treatments have been developed to treat PTSD. There are five main goals for treating PTSD with medications, including a reduction of the core symptoms such as anxiety and flashbacks, an improvement in stress resilience, an improvement in the quality of life, and a reduction in disability and comorbidity (15). As Brunello et al. notes, it is important to maintain wellness and prevent relapse (6).

Concurrent with HPA axis dysfunction, disruption of glutamatergic, serotonergic, and adrenergic systems is a fundamental cause of the structural and functional abnormalities which contribute to the symptoms of PTSD. Such symptoms include hyperarousal and reexperiencing feelings associated with the trauma through flashbacks or nightmares (11). The persistent re-experiencing of traumatic events may cause an increase in $\mathrm{CRH}$ levels, which damages the hippocampus, an important region of the brain associated with learning and memory $(16,17)$. With psychological trauma, a decrease in hippocampal volume has been observed (6). This volume decrease, when coupled with hypersensitivity of the HPA axis, is associated with a reduction of cognitive functioning drastically affecting the performance of affected individuals (18). Selective Serotonin Reuptake Inhibitors (SSRIs) have been successfully used to treat these hyperarousal symptoms purported to be caused by a decrease in hippocampal volume. SSRIs are commonly used to treat depression and there is some evidence that they may promote neurogenesis, which might be the therapeutic mechanism by which these medications effect changes in behaviour (18). For example, Bremner and Vermetten demonstrated a $4.6 \%$ increase in the volume of the hippocampus and an improvement in memory of PTSD patients through treatment with the SSRI Paroxetine (18).

Many hormones and receptors in the glutamatergic, serotonergic, and adrenergic systems have been identified as key factors in memory and perception, one of which is the gamma-aminobutyric acid receptor (GABA-R) (11). Following sexual abuse and the development of PTSD, the dysregulation of the HPA axis can stimulate the adrenergic system, activating GABA-R (15). The multifaceted interactions between these systems may explain the connections of emotions with factual memory. It has been proposed that while a traumatic memory is re-lived during a flashback, there is an increase in the stimulation of GABA-R caused by an increase in the release of endogenous benzodiazepines (15). To control the overstimulation of GABA-R and thereby control anxiety and flashbacks, benzodiazepine inhibitors such as flumazenil have been used successfully (11). This has also been achieved with clonidine to stop nightmares by decreasing the release of catecholamines, a key component of the anxietyprovoking 'fight or flight' response of the autonomic nervous system (19).

The immune system is reciprocally regulated by the neural and endocrine systems and can also be affected by PTSD (20). PTSD often co-occurs with various inflammatory diseases, likely due to HPA axis dysregulation affecting the immune system (21). Immunomodulation is therefore important to avoid this subsequent dysregulation of the immune system and this can be achieved with SSRIs such as Fluvoxamine.

Fluvoxamine has been shown to be effective in decreasing the hyperresponsiveness of the HPA axis, thereby increasing levels of interleukins and other essential immune factors (22). Interestingly, there is a sexual dimorphism in immune functioning, as men with PTSD were found to have an inhibited cell-mediated immunity, while women showed enhanced cellmediated immunity (21). A better understanding of this is necessary and it is important to consider sexual dimorphism for immunomodulation.

Other drug treatment options are available for PTSD including Tricyclic Antidepressants (TCA), Monoamine Oxidase Inhibitors (MAOI), SSRIs, serotonin antagonists, and anticonvulsants and are described in Table 1 (23). Although there are some promising studies for medications, reviews of pharmacotherapies for PTSD have revealed that most treatments are inadequate, aside from some supportive evidence of SSRI effectiveness (24). Therefore it is useful to look towards other disciplines for additional treatment.

\section{PSYCHOLOGY OF PTSD AND COGNITIVE FACTORS}

Although the pathology associated with PTSD has a biological basis, the treatment need not be restricted to drugs. For example, a serious consequence of HPA axis dysregulation is the effect on the steroid hormones, namely estrogen and testosterone, which are also modulated through this axis (25). As a result, some survivors of sexual assault can become infertile due to sex steroid dysregulation. Interestingly, research indicates that fertility may be restored with cognitive behavioural therapy (CBT), just one example of many where psychological intervention was used to treat a biologically based malady (26).

After an assault, survivors experience The Rape Trauma Syndrome (RTS), which affects not only victims of rape, but also victims of all types of sexual violence and would perhaps be better labelled as Sexual Assault Trauma Syndrome. RTS is characterized by three phases (27). The Acute Phase occurs immediately following the assault when the survivor is in crisis and experiences a wide range of emotional reactions. These 
reactions may be categorized as Expressive, such as shaking, crying or yelling; or Controlled such as flattened affect, appearing outwardly calm and subdued. The second phase is Outward Adjustment, when the survivor focuses less on the assault, often with a high level of denial, and involves themselves in normal daily activities. The final phase is Long Term Reorganization, in which the survivor integrates the assault into their view of themselves and resolves their feelings about the assailant. There are many psychological effects to consider following a sexual assault such as feelings of shame, guilt, anxiety or depression (9). These feelings may be even stronger and more harmful if the survivor does not receive support from their family, friends or authorities (9).

Cognitive factors play a large role in the onset, severity, and outcome of PTSD after sexual assault (28). These factors include mental defeat and confusion,

Table 1. Summary of pharmacologic treatment options for PTSD

\begin{tabular}{|c|c|c|}
\hline Drug classification & Drug Name & Effects on PTSD improvement \\
\hline \multirow[t]{2}{*}{ Tricyclic antidepressants } & Amitryptiline & $\begin{array}{l}\text { - } 50 \% \text { of treated patients had a final CGI-I } 1 \text { score of } 1 \text { or } 2 \text { ("very } \\
\text { much" or "much improved") as compared to } 17 \% \text { for placebo }\end{array}$ \\
\hline & Imipramine & $\begin{array}{l}-25 \% \text { decrease from baseline in IES }{ }^{2} \text { scores for treated patients as compared } \\
\text { to } 5 \% \text { for placebo } \\
\text { - } 65 \% \text { of treated patients were found to improve on a Global Scale as } \\
\text { compared to } 28 \% \text { for placebo }\end{array}$ \\
\hline \multirow{3}{*}{$\begin{array}{l}\text { Monoamine Oxidase } \\
\text { Inhibitors }\end{array}$} & Phenelzine & - $45 \%$ decrease from baseline in IES score as compared to $5 \%$ for placebo \\
\hline & Brofaromine & $\begin{array}{l}\text { - Reductions in PTSD symptoms were reported, however no difference was } \\
\text { found between treatment group and placebo group }\end{array}$ \\
\hline & Moclobemide & $\begin{array}{l}\text { - } 11 \text { of } 20 \text { participants no longer met the criteria for PTSD at the end of a } 12 \\
\text { week trial }\end{array}$ \\
\hline \multirow[t]{5}{*}{$\begin{array}{l}\text { Selective Serotonin } \\
\text { Reuptake Inhibitors }\end{array}$} & Fluoxetine & $\begin{array}{l}\text { - } 85 \% \text { of treated patients showed improvement on a Global Rating Scale as } \\
\text { compared to } 62 \% \text { of patients taking placebo } \\
\text { - Response rate on High End State Functioning was } 41 \% \text { for treatment group } \\
\text { and } 4 \% \text { for placebo }\end{array}$ \\
\hline & Sertraline & $\begin{array}{l}\text { - } 43 \% \text { decrease in CAPS }{ }^{3} \text { score for treatment group as compared to } 31 \% \text { for } \\
\text { placebo }\end{array}$ \\
\hline & & $\begin{array}{l}\text { - } 39 \% \text { decrease in DTS } 4 \text { score for treatment group as compared to } 24 \% \text { for } \\
\text { placebo }\end{array}$ \\
\hline & Paroxetine & $\begin{array}{l}\text { - 50\% decrease in DTS score for treatment group } \\
-40 \% \text { decrease in IES score for treatment group }\end{array}$ \\
\hline & Fluvoxamine & $\begin{array}{l}\text { - } 64 \% \text { of patients had a Duke Improvement score or } 1 \text { or } 2 \\
\text { - Significant reductions in mean scores for all efficacy scales used (TOP-8 }{ }^{5} \text {, } \\
\text { DTS, IES) }\end{array}$ \\
\hline 5-HT2 Antagonist & Nefazodone & $\begin{array}{l}\text { - A decrease in PTSD severity on a Primary Assessment Scale in both combat } \\
\text { veterans and civilians was observed }\end{array}$ \\
\hline \multirow[t]{3}{*}{ Anticonvulsants } & Lamotrigine & $\begin{array}{l}\text { - } 50 \% \text { of patients in treatment group responded as compared to } 25 \% \text { for } \\
\text { placebo group* }\end{array}$ \\
\hline & Carbamazepine & - 70\% of patients had a response of "moderate" or "very much" improvement \\
\hline & Valproate & $\begin{array}{l}\text { - Approximately } 70 \% \text { of patients had a response of "moderate" or "very } \\
\text { much" improvement }\end{array}$ \\
\hline
\end{tabular}

1. Clinical Global Impressions-Improvement Scale

2. Impact of Events Scale

3. Clinician Administered PTSD Scale

4. Davidson Trauma Scale

5. 8-Item Treatment-Outcome PTSD Scale 
negative appraisal of emotions and symptoms, avoidance and perceived negative responses from others (5). If the survivor of sexual assault believes that others have failed to react in a positive and supportive manner, there is a greater risk of PTSD (9). It has been suggested that trauma recovery is characterized by a reprogramming, integration, and habituation to the traumatic images, leading to a restoration of a sense of safety (29). Over time, PTSD symptoms will decrease, the survivor will be less preoccupied with blame towards self and others, and a will achieve a regained sense of control (29).

Events perceived as uncontrollable are much more distressing than controllable events, therefore with uncontrollable events such as sexual assault, survivors will attempt to attribute blame to behavioural, dispositional or vicarious causes (30). Behavioural selfblame has the potential to be adaptive as it promotes the belief that negative outcomes can be avoided in the future; whereas dispositional self-blame attributes the traumatic event to one's personality and this thinking does not give a sense of future control (30). Vicarious control refers to the perception that some other person or entity had control over the occurrence of that event (30). Attributing blame in any of these ways focuses on the past and is associated with poorer outcomes in PTSD. To improve PTSD, treatment outcomes emphasis should be on controlling the present situation and what can be done about the impact of the event, rather than how it could have been avoided or can be avoided in the future (30). In view of the fact that control over the recovery process results in lowered distress levels, fostering this form of control could be an important component of interventions for sexual assault survivors (30).

Early intervention is critical for sexual assault victims because the level of distress immediately following the assault is strongly correlated to future pathologies and PTSD (31). In a study collecting self-reports from survivors of assault that assessed their degree of support and psychological distress during and immediately following the rape, it was found that high distress levels significantly predicted increased levels of fear and anxiety in the months following the assault (31). As the level of distress is strongly correlated to PTSD symptoms, an attempt to decrease levels of distress immediately following sexual assault may result in a more positive treatment outcome. When survivors seek medical assistance, the forensic rape exam can be very traumatizing (32). Resnick et al., demonstrated that meeting with a rape crisis counsellor or viewing a video before a forensic rape exam depicting in detail what to expect during the exam, resulted in decreased levels of stress after the exam in test groups compared to the non- video control group (32). Of all the eligible women, $81 \%$ agreed to participate in this video study, indicating that this is a feasible way to decrease distress and reduce future PTSD development following the physical examination.

Since November 1999, the Edmonton Capital Health Authority has run the Sexual Assault Response Team of Edmonton (SARTE) (33). This form of intervention has been very effective in lowering levels of distress in the hospital setting. SARTE consists of a team of nurses who are sensitized to the particular needs of survivors, and specialized in dealing with victims of sexual assault. When working with survivors, the nurses explain in detail the procedures they will perform, assist patients in reporting to the police, and maintaining an open environment where the survivor is able to make as many decisions on their own as possible (28).

\section{PSYCHOTHERAPY TREATMENT OPTIONS FOR PTSD}

In addition to promising social programs, there are many therapies focussing on the psychological aspect of PTSD. CBT focuses on changing thought patterns and cognitions to decrease negative emotions, develop skills to cope with anxiety and negative thoughts, restore effective social skills, and develop ways to manage anger and future trauma symptoms (9).

Eye Movement Desensitization and Reprocessing (EMDR) is an Information Processing Therapy that combines elements of CBT, psychodynamic, interpersonal, experiential and body-centred therapies to treat PTSD (34). During EMDR, the client thinks of past or present traumatic experiences while concurrently focusing on a stimulus such as auditory tones, tactile stimulation, or visual cues (34). This leads to dual attention, changing the processing of the traumatic memories and decreasing anxiety when thinking about the traumatic experience. It has been suggested that PTSD is due to an inability to adequately process the trauma and EMDR may be useful in this reprocessing (35). In an EMDR study by Rothbaum, only $10 \%$ of participants who were treated with EMDR therapy exhibited PTSD symptoms after treatment, compared to $88 \%$ of non-treatment control patients (36). Although the role of the eye movements has been contested, EMDR is proving to be an effective treatment option for PTSD (36).

Group therapy can be very effective to help survivors focus on the present and share experiences with others in a safe and empathetic environment. According to one survey, over half of the women who experienced sexual assault within the previous five years never told anyone about their trauma (37). This silence can have an important impact on the development of PTSD, as the 
degree of support received can influence symptom severity (5). Individuals who receive bad or no support report more PTSD symptoms (28).

Psychodynamic therapy focuses on the emotional conflicts caused by the trauma, especially as they pertain to early life experiences. This helps to develop self-esteem, effective ways of thinking and coping, and may be used to treat PTSD (9). As discussed earlier, focusing on the past is associated with poorer adjustment and present control should be encouraged (30). As such, psychodynamic therapy may be less effective than other therapies for assault victims.

New psychological therapies and treatments are continually developed as older ones are re-evaluated. For example, trauma debriefing is common practice to reduce distress and aid in recovery immediately following a traumatic experience. Recently, it has been found that debriefing did not prevent the onset of PTSD and may even increase the risk of PTSD symptoms, demonstrating that treatments should be continuously evaluated and modified (38).

Both pharmacotherapy and CBT are viable treatment options for PTSD, however it is clear that empowering victims by giving back control is crucial in successful recovery. In one study, survivors were asked to choose between CBT with prolonged exposure to traumatic stimuli or the SSRI medication Sertraline (39). Participants of the study rated CBT as more credible and had more positive feelings towards this treatment option, citing effectiveness and potential side effects as the two primary factors in their decision. When presenting treatment options, it is important to explain both options and put side effects in perspective. Many women do not want pharmacotherapy and the therapy provider should give victims of assault a choice when deciding treatment options, to help them regain a sense of control (39).

\section{SOCIOLOGICAL ISSUES CONTRIBUTING TO PTSD}

Recovery from psychological issues due to sexual assault related PTSD is not solely an individual challenge, but also a challenge for those close to the affected individual (27). The recovery process is also a sociological issue and societal aspects should not be ignored. Research indicates that initial levels of distress and perceived control are key factors in the onset and severity of PTSD (31). Perceived positive regard and support has also been shown to be important to recovery (28). Less than half of individuals who have been sexually assaulted disclose the assault to others and it is clear that many are not getting the support they require. As a large part of the recovery process is related to a solid support network, part of the discussion of treatment and prevention of PTSD should be sociologically directed by targeting attitudes towards and origins of sexual assault with considerations of how these attitudes may create a rape-prone society and allow for such a high frequency of sexual assault.

There are many rape myths in our society, for example, beliefs that individuals lie about being assaulted, perpetrators are easily identifiable, or that men cannot be sexually assaulted. These myths promote negative attitudes and victim-blaming philosophies. Education is the first step in preventing PTSD associated with assault. The number of sexual assault victims willing to tell someone about their experience is increasing, potentially because there is less of a stigma attached to it today and there are more voluntary and professional support agencies (37). Although this shows some improvement, many individuals still have attitudes that sex role stereotyping, adversarial sexual beliefs, and acceptance of interpersonal violence, all of which lead to greater acceptance of rape myths (40). Although sexual assault programs are becoming more pervasive across college campuses, these programs are not always effective in implementing meaningful changes in cognition and behaviour (32). By understanding the failures of education programs, directions for improvement are found. Increasing program length may allow for more meaningful changes in cognition and behaviours to occur (41). Targeting the attitudes that lead to greater acceptance of rape myths may lead to a more supportive community for victims of sexual assault. Education is vital in rape prevention and to foster a supportive environment for survivors of this crime, but it is clear that more research is needed to improve the efficacy of these programs.

Many survivors who disclose their assault to others experience secondary victimization. Secondary trauma occurs when survivors seek assistance from medical, legal or healthcare professionals, but these professionals often exhibit and use victim-blaming behaviours (42). Contact with many services especially those which do not specialize in sexual assault traumatization, can increase survivors' psychological and physical distress (43).

Society contributes to the acceptance of rape myths through individuals the survivor solicits for help as well as by contributing to the negative cognitions of the survivors themselves. Negative cognitions foster selfblame and increase the risk of post-assault psychopathologies, likely contributing to the low disclosure rates.

\section{CONCLUSION}

Recovery from rape trauma is a deeply personal and 
highly individualized journey. As knowledge of the pathophysiology of PTSD improves, more effective medications are developed to treat and manage the biological aspects of this disorder. Psychological therapies are available to assist survivors in their recovery. The number of rape prevention centres and education programs are on the rise with aims to debunk rape myths, change victim-blaming attitudes and destigmatize the subject. One of the most important aspects in assisting the recovery process is empowering the survivor and putting control back into their hands. The three-treatment modalities for the biological, psychological, and sociological impacts should not remain mutually exclusive. Physicians, therapists, law enforcement agencies, and family and friends must work together to find the meaning of recovery from the perspective of the survivors and to understand what conditions will facilitate growth and recovery. When the therapies available to treat sexual-assault-related PTSD are brought together during the right stages in the recovery process to form a comprehensive treatment of the highly individual survivor, greater success in decreasing the rate of PTSD associated with sexual assault may be achieved.

\section{REFERENCES}

1. Canadian Federation of Students. No Means No - Facts about Date Rape/Drug Rape. Canadian Federation of Students 1999 Fact Sheet, 6(2) Retrieved March 26, 2005, from http://www.cfs-fcee.ca/html/english/research/factsheets/fs-6(2)nmn.pdf; 1999.

2. Rose, DS. Worse than Death: Psychodynamics of Rape Victims and the Need for Psychotherapy. The American Journal of Psychiatry 1986; 43(7): 817-824.

3. LoVerso, T. Survey of Unwanted Sexual Experience among University of Alberta Students. Retrieved March 26, 2005 from http://www.uofaweb.ualberta.ca/sac/nav01.cfm?nav01=27459; 2001.

4. Matsakis, A. I Can't Get Over It: Handbook for Trauma Aurvivors. Oakland, California: New Harbinger Publications; 1996.

5. Dunmore E, Clark DM, Ehlers A. Cognitive Factors Involved in the Onset and Maintenance of Post Traumatic Stress Disorder (PTSD) after Physical or Sexual Assault. Behaviour Research and Therapy 1999; 37: 809-829.

6. Brunello N, Davidson JRT, Deahl M, Kessler RC, Mendlewicz J, Racagni G et al. Posttraumatic Stress Disorder: Diagnosis and Epidemiology, Comorbidity and Social Consequences, Biology and Treatment. Neuropsychobiology 2001; 43: 150-162.

7. Butcher JN, Mineka S, Hooley JM. Abnormal Psychology 12th Edition. Boston, MA: Allyn and Bacon; 2004.

8. American Psychiatric Association. Diagnostic and Statistical Manual of Mental Disorders (4th ed., rev.). Washington, DC: American Psychiatric Association; 2000.

9. National Center for Post Traumatic Stress Disorder. Epidemiological Facts About PTSD - A National Center for PTSD Fact Sheet. Retrieved April 1, 2005 from http://www.ncptsd.va.gov/facts/general/fs_epidemiological.htm 1; 2005.

10. Creamer M, Burgess P, McFarlane AC. Post-traumatic stress disorder: Findings from the Australian National Survey of Mental Health and Well-being. Psychol. Med 2001; 31(7): 12371247.

11. Nutt JD. The Psychobiology of Post Traumatic Stress Disorder. J Clin Psychiatry 2000; 61(5): 24-29.

12. Gold PW, Goodwin FK, Chrousos GP. Clinical and Biochemical Manifestations of Depression: Relation to the Neurobiology of Stress, Part II. N Engl J Med 319: 412-420; 1988.

13. Tizabi Y, Aguilera G, Gilad GM. Age Related Reduction in Pituitary Corticotrophin Releasing Hormone Receptors in Two Rat Strains. Neurobiol Aging 1992; 13: 227-230.

14. Perry BD, Pollard RA, Blakley TL, Baker WL, Vigilante D. Development of the Brain: How States Become Traits. Infant Mental Health Journal, July 25. Retrieved December 8, 2005 from http://www.trauma-pages.com/perry96.htm; 1995.

15. Davidson J, Glover V, Clow A, Kudler H, Meador K, \& Sandler M. Tribulin in Posttraumatic Stress Disorder. Psychol Med 1988; 18(4): 833-836.

16. VanVoorhees E, Scarpa A. The Effects of Child Maltreatment on the Hypothalamic-Pituitary-Adrenal Axis. Trauma, Violence and Abuse 2004; 5(4): 333-352.

17. Maren S. LTP in the Amygdala: a Mechanism for Emotional Learning \& Memory. Trends in Neurosciences 1999; 22: 561567.

18. Bremner JD, Vermetten E. Neuroanatomical Changes Associated with Pharmacotherapy in Posttraumatic Stress Disorder. Ann NY Acad Sci 2004; 1032: 154-157.

19. Harmon RJ, Riggs PD. Clonidine for Posttraumatic Stress Disorder in Preschool Children. J Am Acad Child Adolesc Psychiatry 1996; 35: 1247-1249.

20. Boscarino, JA. Posttraumatic Stress Disorder and Physical Illness: Results from Clinical and Epidemiological Studies. Ann NY Acad Sci 2004; 1032: 141-153.

21. Tucker P, Ruwe WD, Masters B, Parker DE, Hossain A, Trautman RP, Wyatt DB. Neuroimmune and Cortisol Changes in Selective Serotonin Reuptake Inhibitor and Placebo Treatment of Chronic Posttraumatic Stress Disorder. Biol Psychiatry 2004; 56: 121-128.

22. Rinne T, de Kloet ER, Wouters L, Geokoop JG, de Rijk RH, van den Brink W. Fluvoxamine Reduces Responsiveness of HPA Axis in Adult Female BPD Patients with a History of Sustained Childhood Abuse. Neuropsychopharmacology 2003; 28: 126132.

23. Davidson JRT. Pharmacotherapy of Posttraumatic Stress Disorder: Treatment Options, Long-Term follow-Up, and Predictors of Outcome. J Clin Psychiatry 2002; 61(5): 52-56.

24. Solomon SD, Gerrity ET, Muff AM. Efficacy of Treatments for Posttraumatic Stress Disorder. JAMA 1992; 268: 633-638.

25. Rivier C, Rivier J, Vale W. Stress Induced Inhibition of Reproductive Functions: Role of Endogenous Corticotrophin Releasing Factor. Science 1986; 231: 607-609.

26. Berga SL, Daniels TL, Gules DE. Women with Functional Hypothalamic Amenorrhea but not Other Forms of Anovulation Display Amplified Cortisol Concentrations. Fertil Steril 1997; 67: 1024-1030.

27. Volunteer Training Manual. Sexual Assault Centre of Edmonton. Edmonton, AB; 1999.

28. Koss MP, Figuerdo AJ. Change in Cognitive Mediators of Rape's Impact on Psychosocial Health Across 2 Years of Recovery. Journal of Consulting and Clinical Psychology 2004; 72(6): 1063-1072.

29. Brewin CR, Dalgleish T, Joseph S. A Dual Representation Theory of Posttraumatic Stress Disorder. Psychological Review 1996; 103: 670-686.

30. Frazier PA. Perceived Control and Distress Following Sexual Assault: A Longitudinal Test of a New Model. Journal of 
Personality and Social Psychology 2003; 84(6): 1257-1269.

31. Girelli SA, Resick PA, Marhoefer-Dvorak S, Hutter CK. Subjective Distress and Violence During Rape: Their Effects on Long-Term Fear. Violence and Victims 1986; 1: 35-45.

32. Resnick H, Acierno R, Holmes M, Kilpatrick DG, Jager N. Prevention of Post-Rape Psychopathology: Preliminary Findings of a Controlled Acute Rape Treatment Study. Journal of Anxiety Disorders 1999; 13(4): 359-370.

33. Capital Health. Sexual Assault Response Team. Community Sector Pamphlet, March 2004; 2004.

34. Shapiro F. EMDR as an Integrative Psychotherapy Approach: Experts of Diverse Orientations Explore the Paradigm Prism. Washington, DC: American Psychological Association Books; 2002.

35. Foe EB, Steketee G, and Rothbaum B. Behavioural/Cognitive Conceptualizations of Posttraumatic Stress Disorder. Behaviour Therapy 1989; 20:155-176.

36. Rothbaum BO. A Controlled Study of Eye Movement Desensitization and Reprocessing in the Treatment of Posttraumatic Stress Disordered Sexual Assault Victims. Bulletin of the Menninger Clinic 1997; 61(3): 317-334.

37. British Crime Survey. Rape and Sexual Assault of Women: Findings from the British Crime Survey. Home Office Research Study 159:1-6 Retreived April 32005 from http://www.homeoffice.gov.uk/rds/pdfs2/r159.pdf; 2002.

38. Cuijpers P, Van Straten A, Smit, F. Preventing the Incidence of New Cases of Mental Disorders: a Meta-Analytic Review. J Nerv Ment Dis 2005; 193: 119-125.

39. Zoellner LA, Feeny NC, Cochran B, Pruitt L. Treatment Choice for PTSD. Behaviour Research and Therapy 41:879-886; 2003.

40. Burt MR. Cultural Myths and Supports for Rape. Journal of Personality and Social Psychology 1980; 38: 217-230.

41. Breitenbecher $\mathrm{KH}$, Scarce $\mathrm{M}$. An Evaluation of the Effectiveness of a Sexual Assault Education Program Focusing on Psychological Barriers to Resistance. Journal of Interpersonal Violence 2001; 16(5): 387-407.

42. Campbell R, Barnes HE, Ahrens CE, Wasco SM, ZaragozaDiesfeld Y, and Sefl T. Community Services for Rape Survivors Enhancing Psychological Well-Being or Increasing Trauma? Journal of Consulting and Clinical Psychology 1999; 67(6): 847-858.

43. Campbell R, Wasco SM, Ahrens CE, Sefl T, Barnes HE. Preventing the "Second Rape": Rape Survivors' Experiences with Community Services Providers. Journal of interpersonal violence 2001; 16(12): 1239-1259.

Kaitlin A. Chivers-Wilson is an undergraduate student in the faculty of sciences at the University of Alberta (Edmonton, AB, Canada). She intends to enter graduate studies in the Department of Psychiatry at the University of Alberta in 2006. Her research interests are diverse, with a particular interest in women's health. Kaitlin is passionate about raising awareness of sexual assault and has volunteered at the University of Alberta Sexual Assault Centre since 2003, providing crisis intervention, information and support to sexual assault survivors and their supporters, as well as facilitating education programs to student groups across campus. 